\title{
Visão Baseada em Recursos nas Instituições de Ensino Superior de Fortaleza: uma Análise Ex-Ante e Ex-Post à LDB/ 96
}

\section{Resource Based View and the Collleges in Fortaleza: an Analysis Before and After the LDB/96}

Maise Soares Pereira* Mestre em Administração de Empresas pela UNIFOR, Fotaleza/CE, Brasil.

Sérgio Henrique Arruda Cavalcante Forte

Doutor em Administração pela FGV-EAESP. Professor Titular e Coordenador do CMA/UNIFOR, Fortaleza/CE, Brasil.

*Endereço: Rua General Couto de Magalhães, 1155, apto. 502, Higienópolis, Porto Alegre/ RS,90540-131.E-mail:maise.pereira@oi.com.br 


\title{
Resumo
}

As Instituições de Ensino Superior (IES) de Fortaleza passaram por grandes mudanças em seu cenário competitivo, principalmente após a instituição da Lei de Diretrizes e Bases de 1996 (LDB/96). Aproveitando a caracterização específica de duas épocas distintas quanto à competição do mercado, esta pesquisa pretendeu avaliar a teoria da Visão Baseada em Recursos (VBR) em dois contextos estratégicos, a exemplo dos estudos realizados por Miller e Shamsie (1996) nos estúdios de Hollywood. Com o objetivo de identificar quais recursos ou competências foram e são importantes para as IES de Fortaleza, nos períodos pré e pós LDB/96, foram entrevistados Diretores e Vice-Reitores das IES que atuavam e atuam no período pesquisado. Os questionários aplicados, adaptados de Thompson e Cole (1997), permitiram a identificação dos sete recursos mais relevantes e os três recursos menos relevantes para os diferentes contextos ambientais. Os resultados mostraram que, apesar da existência de um conjunto de recursos comuns aos dois momentos da história, as características ambientais de cada época traduziram necessidades de competências específicas, evidenciando a importância de adaptação da VBR aos contextos externos onde se inserem as instituições.

Palavras-chave: visão baseada em recursos; competências; capacidades dinâmicas; estratégia; ensino e pesquisa em administração.

\begin{abstract}
Colleges in Fortaleza have been through major changes in its competitive market, mainly after the institution of the "Diretrizes e Bases" regulation law in 1996. Considering the two distinct periods of competitive environment (before and after 1996), this research tried to evaluate the Resource Based View theory in strategics contexts as it was investigated by Miller and Shamsie (1996) in the Hollywood studios. Aiming to identify which resources were important to Fortaleza colleges before 1996 and those which still are core after that, 10 Deans were interviewed from the most traditional and biggest colleges in town. The questionnaire, adapted from Thompson and Cole's (1997), allowed to identify the seven more and the three less relevant resources to different context environments. Results showed that, despite a number of common core competencies to those distinguished moments, the competitive characteristics of each period required specific and differentiated resources, indicating the need of RBV theory to fit external environment.
\end{abstract}

Key words: resource-based view; competences; dynamic capabilities; strategy; teaching and researching in administration. 


\section{INTRODUÇÃO}

De acordo com as estatísticas do Ministério da Educação [MEC]/Instituto Nacional de Estudos e Pesquisas Educacionais Anísio Teixeira [INEP] (2005), de 1994 a 2003 houve um aumento de 1734\% nas matrículas realizadas e o aumento de $118,3 \%$ na quantidade de IES. Weinberg (2000) ressalta que, nas estimativas do MEC de 2003 para 2008, o contingente de brasileiros com diploma superior evoluirá de $14 \%$ para $30 \%$.

A partir de 1994, a ampliação da rede privada no ensino superior ocorreu em função de vários artigos que constituem objeto da Lei de Diretrizes e Bases [LDB] no. 9.493/96. Destacam-se, a seguir, as principais mudanças no ensino superior, promovidas por ocasião da LDB de 1996, no tocante a aspectos como qualidade do ensino, autonomia para as escolas e universidades, flexibilidade, diversificação de cursos e valorização do magistério: autorização de cursos seqüenciais; aceleração de estudos; inexistência de frequiência mínima de alunos; liberdade de seleção de ingresso de alunos; abertura a instituições nãouniversitárias (centros universitários, faculdades integradas, faculdades, escolas superiores, institutos superiores e centros tecnológicos); existência de universidades especializadas por campo do saber; estímulo a investimentos da iniciativa privada; qualificação do corpo docente universitário (pelo menos um terço do corpo docente com titulação acadêmica de mestrado ou doutorado e um terço do corpo docente em regime de tempo integral); autonomia às universidades, com permissão para a criação, organização e extinção de seus cursos de graduação, fixação de currículos e número de vagas; conferência degraus, diplomas e outros títulos; criação de processo regular de avaliação do ensino pelo MEC/INEP (2005).

Desde que o número de IES de Fortaleza mostrava potenciais de multiplicação, tendo a LDB/96 como um de seus motivadores principais, as instituições de longa tradição precisaram movimentar-se para aprender a competir em nova realidade. Este tipo de movimento vem demandando, necessariamente, elaboração ou revisão do planejamento estratégico das instituições, visando não somente à sobrevivência, mas à manutenção da liderança de mercado.

A avaliação dos posicionamentos competitivos das IES pode ser estudada sob diversos prismas estratégicos. Neste estudo, a intenção consistiu em avaliá-los à luz da teoria da Visão Baseada em Recursos, doravante chamada VBR. Esta opção deveu-se a três razões principais: 1) a extensa produção de artigos sobre posicionamentos estratégicos baseados na análise estrutural das indústrias de 
Porter (1986); 2) a carência de maior número de estudos empíricos sobre a VBR na literatura existente (Fahy, 2000); e 3) a oportunidade de evidenciar as condições ambientais em que a VBR contribui para a obtenção de vantagem competitiva como conceito dinâmico. Isto significa demonstrar não um possível antagonismo, mas antes um complemento ou mesmo reforço às teorias estratégicas baseadas em organizações industriais (IO theories).

A investigação da VBR em diferentes contextos ambientais permite uma compreensão mais abrangente e atual de seu verdadeiro papel como instrumento auxiliador na avaliação estratégica de uma instituição.

O problema central da pesquisa situa-se, então, na direção da dinamicidade dos recursos estratégicos ou o que se chama de competências dinâmicas (Vasconcelos \& Cyrino, 2000) e divide-se nas seguintes questões: (1) Houve mudança pósLDB/96 dos recursos estratégicos utilizados pelas IES de Fortaleza? (2) As IES públicas e privadas avaliam-se a si próprias de forma diferente com relação aos recursos estratégicos utilizados? e (3) Há priorização no que se refere aos recursos estratégicos tangíveis, intangíveis e capacidades nos contextos pré e pós-LDB/ 96 das IES estudadas?

As hipóteses para verificação da pesquisa por evidências empíricas apontam que: (1) houve mudança dos recursos estratégicos das IES estudadas no período pré e pós-LDB/96; (2) as IES públicas se avaliam em situação melhor que as privadas com relação aos recursos estratégicos adotados; (3) os recursos intangíveis e as capacidades são mais evidentes que os recursos tangíveis no período pós-LDB/96.

O objetivo principal desta pesquisa consistiu em testar a aplicação da VBR aliada ao ambiente externo. Para isso pretendeu-se identificar quais recursos foram e são estratégicos para as IES de Fortaleza, em diferentes contextos ambientais: antes e depois da LDB/96. Estes dois momentos históricos foram assim divididos por evidenciarem as maiores discrepâncias no que se refere ao ambiente competitivo do mercado estudado.

Na primeira parte do trabalho resgatam-se as origens e a evolução da teoria de Visão Baseada em Recursos, avaliando o papel dos recursos na perspectiva atual da VBR e seus pontos de encontro e desencontro com a teoria industrial de Porter (1986); a segunda parte reúne os procedimentos metodológicos necessários à identificação da aplicação da VBR e à classificação de recursos em ambientes dinâmicos e, por último, apresentam-se a caracterização das instituições, os resultados encontrados e conclusão sobre a avaliação de recursos na VBR. 


\section{Evolução da Visão Baseada em Recursos}

A teoria da VBR tem encontrado, na última década, grande espaço na literatura estratégica. Muitas vezes assinalada como contraponto à teoria industrial de Porter (1986), ela tem sido percebida como mais uma contribuição para obtenção de vantagem competitiva.

Apesar de tema considerado ainda recente, a VBR teve seus embriões germinados nos estudos de Chamberlin, 1933 e Robinson, 1933 (como citado em Fahy, 2000). Eles já sugeriam que os ativos e capacitações singulares de cada organização eram os responsáveis pela geração de lucros acima da média, em ambientes de monopólios ou de competição imperfeita. Ainda que datado dos anos 30 , este conceito parece não diferir muito da visão atual da VBR, se consideradas as ressalvas ambientais.

No entanto uma pesquisa mais profunda baseada na heterogeneidade das organizações, realizada por Edith Penrose em 1959, é considerada, pela maioria dos acadêmicos de estratégia, o marco inicial da VBR (Rugman \& Verbeke, 2002). Os estudos de Penrose (1959) continham a gênese do que veio a se chamar Teoria da Firma e indicavam a importância de um conjunto de recursos únicos, determinados pela alta administração, para a elevação da performance da empresa.

O desenvolvimento da teoria estratégica dos anos 70 apresentava uma perspectiva clássica inicial de definição de objetivos, com avaliação na melhor combinação (fit) de capacitações internas e oportunidades externas (Ansoff, 1990). Porter (1986), na obra "Estratégia Competitiva", revisitou esse esquema, aprofundando o detalhe do ambiente externo por meio da análise estrutural da indústria. A partir de então, os modelos de organização industrial $(I O)$ passaram a ser amplamente estudados e as definições de estratégia e posicionamento concentraram-se na análise ambiental das cinco forças descritas por Porter (1986).

Um resgate do estudo da importância de recursos estratégicos para a performance das empresas surgiu com a publicação de um artigo de Wernerfelt (1984) no Strategic Management Journal. Este estudo trouxe algumas evidências que indicaram um aumento de performance em empresas, mais bem explicado pela força de seus recursos do que pela sua posição de mercado. Esta idéia tomou impulso com outros pesquisadores (Amit \& Schoemaker, 1993; Barney, 1986; Peteraf, 1993) que persistiram na tentativa de compreender a razão de diferentes desempenhos entre empresas de mesma indústria, em ambientes de ampla competição. 
Esse debate tem tomado grande espaço na pauta acadêmica; mas parece que alguma evolução na compreensão mais abrangente da VBR é atingida, quando se avalia a Visão Baseada em Recursos como fonte de vantagem competitiva.

Com o objetivo de alcançar vantagem competitiva sustentável, obtendo retornos e performances superiores à competição, a VBR identifica a escolha de um conjunto de recursos únicos, combinados em competências e habilidades que proporcionem o atingimento desta vantagem (Fahy, 2000). Desta definição de VBR dois conceitos importantes devem ser ressaltados: a singularidade dos recursos necessários e a sustentabilidade da vantagem competitiva. Isto implica aceitar a natureza dinâmica da vantagem competitiva e a compreensão de que nem todos os recursos possuem o mesmo potencial de contribuição para esta vantagem.

Vantagens competitivas sustentáveis estão mais para caminhos a serem trilhados do que para um destino a ser alcançado (Chaharbaghi \& Lynch, 1999). Para se manter no tempo, uma organização precisa mudar suas características de acordo com a mudança do contexto ambiental. Uma moderna visão da VBR começa a compreender que os recursos não são estáticos e imutáveis. Eles devem ser analisados como um modelo dinâmico que avalie a contribuição dos recursos existentes para as oportunidades atuais e a capacidade de geração de novos recursos necessários para a obtenção de vantagem competitiva em ambientes futuros.

A VBR tem indicado, assim, que a identificação, escolha e desenvolvimento dos recursos estratégicos para a performance da organização são responsabilidades da alta administração. Isto sugere que somente alguns recursos são capazes de gerar valor para o consumidor e garantir vantagem competitiva.

\section{Recursos Essenciais Na VBR}

Barney (1991) é um dos autores mais citados na caracterização dos recursos estratégicos, geradores de diferencial competitivo para as organizações. Ele propõe que recursos geradores de vantagem competitiva devem atender a quatro condições básicas: 1) possuírem valor; 2) serem raros ou escassos; 3) serem difíceis de imitar; e 4) serem difíceis de substituir. Muitos outros pesquisadores contribuíram com características adicionais, como estas: durabilidade, transparência, dificuldade de transferência e de replicação (Grant, 1991). Collis e Montgomery (1995) sugerem cinco condições e Amit e Schoemaker (1993) relacionam oito características necessárias a recursos estratégicos, incluindo, além das descritas anteriormente: superioridade competitiva, complementaridade e ajuste aos fatores estratégicos da indústria. 
Certa polêmica surge na academia, quando se trata da definição de recursos valiosos ou relevantes. Eles são considerados estratégicos para a organização, quando oferecem valor para o consumidor, gerando vantagem competitiva. Ocorre que esse valor é dinâmico e de difícil mensuração, já que se altera de acordo com o ambiente externo.

A escassez dos recursos é fator importante pela dificuldade gerada à competição, para obtenção do mesmo recurso. Se todos tivessem acesso aos mesmos recursos, poderiam obter as mesmas vantagens; portanto um recurso valioso, mas não raro, transforma-se rapidamente em pré-requisito para toda a concorrência, mas não em um ativo com potencial de gerar vantagem competitiva (Nieto \& Perez, 2002).

As dificuldades de imitação e substituição também são elementos centrais da VBR e fazem parte de uma discussão maior sobre as barreiras de duplicação ou mecanismos de isolamento dos recursos estratégicos. As organizações precisam apropriar-se destes ativos essenciais, impedindo o acesso da concorrência. Muitos autores estudaram essas barreiras, definindo-as como diferenciais culturais e nas capacitações das empresas; complexidade e especificidade dos recursos; ambigüidades causais, entre outros (Fahy, 2000).

A durabilidade ou continuidade dos recursos necessários em cada momento é fundamental para a manutenção da vantagem competitiva e, junto com as demais condições de valor, escassez, dificuldade de imitação e substituição, bem como capacidade de apropriação, formam o que Nieto e Perez (2002) chamam de fatores extrínsecos dos recursos. Eles afirmam, ainda, que esses fatores dependem e se relacionam com as outras características intrínsecas da natureza própria de cada recurso, como as seguintes: heterogeneidade, ambigüidade, complexidade, especificidade, duração, imobilidade e dificuldade de transferência.

A presença ou não dessas características e fatores constituem, em suma, fontes sustentáveis de diferencial estratégico. Peteraf (1993) apresenta, em seu artigo The cornerstones of competitive advantage, quatro macrocategorias para posicionar os mesmos elementos na construção da vantagem competitiva: (1) heterogeneidade dos recursos; (2) mobilidade imperfeita; (3) barreiras à competição (ex post); e (4) barreiras à competição (ex ante).

A heterogeneidade define a obtenção de recursos únicos como monopólios ou as chamadas rendas Ricardianas - oriundas da posse exclusiva de determinados ativos - e ainda recursos particulares provenientes de inovação. A mobilidade imperfeita engloba os aspectos de escassez e dificuldade de transferência dos recursos. Barreiras à competição constituem a imposição de limites à concorrência ex post para que a vantagem da organização se sustente no tempo. Isto significa 
tanto desenvolver os mecanismos de isolamento como dificuldades de imitação, substituição e complexidade dos recursos, quanto obter competitividade ex ante à geração de vantagem, como a redução nos custos de implementação das estratégias, garantindo rendas superiores para as organizações.

\section{Tipologia DE ReCuRsos}

A maioria dos autores que pesquisam recursos classificam-nos em três categorias principais: ativos tangíveis, intangíveis e capacidades. Variações na nomenclatura são encontradas, como a classificação em: ativos físicos, humanos e organizacionais (Kotelnikov, 2003); ou ativos de inventário, de habilidades, e de capacidades (Nieto \& Perez, 2002). Há, ainda, divisões dicotômicas, como a realizada por Miller e Shamsie (1996): recursos baseados em propriedade e recursos baseados em conhecimento, que englobam tanto intangíveis quanto capacidades.

De forma geral, os recursos tangíveis, físicos ou baseados em propriedade são relativamente fáceis de contabilizar ou inventariar; compreendem equipamentos, estoques, plantas, terra depósitos, entre outros. Eles apresentam maior facilidade de imitação e são fontes de vantagem competitiva somente quando existem direitos de exclusividade ou controle sobre o recurso, impedindo o acesso a competidores.

Os recursos intangíveis referem-se não somente à reputação, patentes, relacionamentos, mas também às habilidades intelectuais mais complexas e específicas; portanto são mais difíceis de mensurar e imitar.

Os ativos baseados em capacidades têm sido considerados determinantes na geração de vantagem competitiva e se referem às capacidades ou ativos organizacionais. Eles compreendem interações de recursos, conhecimento coletivo, coordenação e integração de habilidades técnicas, criativas e colaborativas. Estas capacidades consistem nas competências essenciais descritas por Prahalad e Hamel (1990), geradoras de diferenciais competitivos para as organizações. Esses ativos, por serem mais complexos, interativos e envolverem uma série de recursos complementares, são os mais difíceis de imitar e de avaliar economicamente.

Thompson e Cole (1997) estudaram quais os conjuntos de recursos organizacionais que, aplicados a determinada dinamicidade do ambiente, eram mais estratégicos e geradores de níveis de desempenhos superiores. Uma relação de 32 competências genéricas foi avaliada em empresas de alta e baixa performance, mensurada nos doze meses anteriores à investigação. A pesquisa capturou a auto-avaliação em termos de desenvolvimento de cada recurso, de 
mais de um respondente em cada empresa investigada. Os resultados demonstraram as opções de conjuntos de recursos mais relacionados com a alta e a baixa performance da empresa.

Apesar de diferentes tipos de recursos contribuírem de forma diversa para a obtenção de vantagem competitiva, eles só se transformam em vantagens, quando compreendidos dentro de uma indústria ou mercado (Kay, 1993), ou seja, seu valor depende do contexto ambiental. Esta afirmação leva a necessárias considerações sobre o posicionamento da VBR com a teoria industrial.

\section{Visão Baseada em Recursos e o Modelo de Porter - Novos DESAFIOS}

A VBR foi compreendida, durante algum tempo, como ferramenta estratégica totalmente voltada para dentro da empresa, contrapondo-se às análises estratégicas baseadas no ambiente competitivo externo, difundidas principalmente pelos estudos de Porter (1986).

No entanto, nem a VBR pode ser entendida como caixa hermética de recursos organizacionais, nem se pode dizer que Porter (1986) efetuou sua análise da concorrência sem avaliar também as capacidades internas das empresas. Para Porter, estratégia competitiva consiste em posicionar um negócio de forma a potenciar o valor dos recursos que o distinguem de seus concorrentes (Porter, 1986 como citado em Forte, Oliveira, \& Silva, 2003, p. 2).

A metodologia de Porter (1986) para análise da concorrência também pode ser utilizada como auto-análise, por meio de quatro componentes diagnósticos: metas futuras, estratégia corrente, hipóteses sobre si próprio e capacidades (grifo nosso). As metas futuras são indicativas de mudanças nas estratégias da empresa; a estratégia corrente envolve as políticas operacionais básicas e suas inter-relações na cadeia de valor; a análise das hipóteses sobre si próprio e a concorrência permite a identificação de movimentos com menor probabilidade de retaliação imediata ou efetiva e, por fim, as capacidades definem os pontos fortes e fracos que capitaneiam vantagens estratégicas ou reações aos movimentos da indústria. Apesar de não se aprofundar em capacidades estratégicas internas, Porter (1986) tampouco as ignora.

Um dos pontos de consideração sobre os modelos de Porter talvez não seja exatamente a falta de análise interna em seus modelos - que pode ser encontrada em seu estudo sobre análise de Cadeia de Valor - mas o foco mais expressivo em 
alguns pressupostos da análise estrutural das indústrias. Carneiro, Cavalcanti e Silva (1997) consideram que a predominância exagerada na análise da indústria serve de fator limitador à capacidade da empresa de inovar, ingressar rapidamente em mercados emergentes ou alterar as escolhas dos clientes em mercados maduros.

Barney (1991) notou que os estudos concentrados em ambiente externo normalmente admitem duas hipóteses. A primeira é a de que as empresas, dentro de uma indústria, têm acesso ao mesmo tipo de recursos; e a segunda é a de que estes recursos são facilmente transferíveis ou copiáveis. A VBR evidencia que estas hipóteses nem sempre se confirmam. Como explicar performances distintas entre empresas da mesma indústria ou grupo estratégico que, segundo Porter (1986), estariam expostas aos mesmos índices de rentabilidade e estratégias genéricas (Ghemawat, 2001)?

Por outro lado, Priem e Butler (2001) evidenciam o que chamam de falácia da VBR: recursos são ditos valiosos, quando exploram oportunidades ou neutralizam ameaças no ambiente em que a empresa está inserta. Essa definição demonstra ser o ambiente externo que determina o grau de valor que cada recurso oferece à vantagem competitiva. Se o ambiente competitivo muda, então os recursos também podem mudar.

Desta forma, o valor de um recurso é amplamente definido por uma fonte exógena à empresa, ou seja, nem os recursos são homogêneos e transferíveis entre as empresas, nem o ambiente externo é imutável, sendo irrelevante para o conjunto de recursos da organização. Uma fórmula de análise de recursos, em conjunto com a análise do ambiente externo, deve ser o caminho mais efetivo para a elaboração de estratégias que gerem vantagens competitivas sustentáveis para as empresas. Foss e Knudsen (2003) descrevem estas duas teorias como os dois lados da mesma moeda chamada vantagem competitiva e esta parece ser a tendência de muitos pesquisadores atuais.

Um estudo que auxilia a confirmação da VBR como ponte entre a teoria baseada na firma e a teoria baseada na indústria (Amit \& Schoemaker, 1993) foi realizado por Miller e Shamsie (1996), sobre os estúdios de filmes de Hollywood (MGM, Warner Bros, Paramount, Universal, 20th Century-Fox, Columbia e United Artists). Eles contextualizaram determinados recursos, de acordo com o ambiente externo vivido em determinadas décadas pelos estúdios. Tomando como base a distinção entre Recursos Baseados em Propriedade (RBP) e Recursos Baseados em Conhecimento (RBC) e a análise de duas eras distintas da história dos estúdios (1936-1950 e 1951-1965), os autores confirmaram as hipóteses testadas: (1) RBP geram maior performance em ambientes previsíveis, mas não em ambientes de incerteza. (2) RBC geram maior performance em ambientes de incerteza, mas 
não em ambientes previsíveis, com base na correlação de variáveis de performance: faturamento, lucros operacionais e market share dos sete estúdios. Este trabalho foi um dos primeiros que tratou de uma integração entre o modelo da VBR e os modelos ambientais, descobrindo o valor dos recursos por intermédio de características externas. Como não se encontrou na literatura de estratégia referencial teórico aplicado às IES sobre a dinamicidade dos recursos (pesquisaram-se 236 papers estrangeiros das bases EBSCO e PROQUEST e todos os papers dos eventos científicos nacionais ENANPAD (Encontro Anual de Pesquisa e Pós-graduação) e 3E (Encontro de Estudo em Estratégia), em um total de 287 trabalhos), utilizou-se da metodologia de Miller e Shamsie (1996), associada ao roteiro da lista de recursos estratégicos de Thompson e Cole (1997).

\section{Desafios da VBR Atual}

Apesar dos novos caminhos que a VBR começou a trilhar, muitos desafios ainda se apresentam para responder a questões similares a estas: como criar e disseminar recursos? Como desenvolver recursos apropriados a contextos futuros? Que recursos contribuem mais para a vantagem competitiva hoje? E amanhã? Como fazer o melhor uso de recursos e capacidades? Que tipos de recursos são mais valiosos e em que contextos? Como os recursos interagem, tornando-se cada vez mais difíceis de imitar ou transferir? Como é possível mensurar esses recursos? Qual a fonte principal de heterogeneidade entre as empresas?

Muitas perguntas carecem de respostas; há ainda poucos estudos empíricos que avaliem a VBR em uma abordagem dinâmica, integrada aos modelos ambientais de estratégia. Esta carência talvez seja explicada pela maior dificuldade de observação, definição e mensuração de recursos mais complexos e capacidades implicitamente integradas.

\section{Metodologia da Pesquisa}

A pesquisa configura-se como descritiva, por meio de uma visão geral e aproximativa, propiciando a descoberta de idéias e dados, para prover análise e critérios acerca de um problema ou situação (Malhotra, 2001) e descrever as características de uma determinada população ou fenômeno (Gil, 1999).

Com o objetivo de avaliar os recursos essenciais geradores de vantagem competitiva para as IES antes e depois da institucionalização da LDB/96, foram efetuados os seguintes procedimentos metodológicos. 
1) Levantamento: (1.1) perfil das IES do Estado do Ceará que nasceram antes da LDB/96; (1.2) relação de recursos envolvidos nessas Instituições; (1.3) avaliação de que recursos são mais adequados a que contextos; e (1.4) autoavaliação de performance da IES quanto aos recursos identificados.

2) Classificação dos recursos levantados de acordo com o modelo de tipologias adaptado da literatura.

Para apoiar a comparação entre as duas épocas caracterizadas no estudo, o universo pesquisado constou das IES que já funcionassem há, pelo menos, dois anos antes de 1996, período considerado razoável para implementar e desenvolver ações estratégicas no mercado (Forte, 2001). Apenas cinco instituições se encaixavam no filtro aplicado e, dentre essas, uma foi descartada por apresentar realidade muito particular e diversa das demais, localizando-se em áreas de, até então, pouca concorrência no interior do Estado. Desta forma, a amostra pesquisada constou de quatro IES de Fortaleza, sendo duas públicas e duas privadas. De cada instituição, selecionaram-se, por conveniência, três representantes da área estratégica, de forma a reduzir um possível viés pessoal em uma resposta única da instituição (Thompson \& Cole, 1997). Dos doze representantes (diretores e vice-reitores) com participação ativa nas discussões de planejamento estratégico das instituições, dez aceitaram ser entrevistados, sendo seis das IES públicas e quatro das privadas.

Para a realização da primeira etapa do estudo, foram acessados os perfis das instituições previamente identificados na pesquisa sobre A Construção e Disseminação da Missão Corporativa nas IES do Ceará (Forte, Pereira, \& Aquino, 2003), que investigou 17 IES da região. Os questionários foram respondidos pelos representantes das IES, em entrevistas pessoais aplicadas pelos autores em outubro de 2003, compostas por quatro questões principais; os respondentes deviam satisfazer ao elenco quadripartite seguinte.

a) Descrever, de forma sumária, o que entendiam por sucesso ou bom desempenho para Instituições de Ensino Superior, considerando que os recursos avaliados deveriam contribuir para o entendimento comum de boa performance. Este dado foi avaliado de forma qualitativa, por meio de análise de conteúdo direta e predominantemente de verificação (Grawitz, 1975).

b) Identificar uma relação de recursos e competências importantes para uma IES no contexto atual, pós-LDB/96. Uma lista de sugestão de 20 recursos foi apresentada, adaptada da pesquisa de Thompson e Cole (1997). Os recursos representavam grupos assim divididos: recursos de 1 a 6 trataram de Visão Estratégica, sua Implementação e Capacidade de Mudança; recursos 
de 7 a 17 trataram de Competências Funcionais e Qualidade; recurso 18 Inovação e Criatividade; e recursos 19 e 20 representaram questões de Ética e Responsabilidade Socioambiental. Foi possível, ainda, a inclusão de novos recursos pelos entrevistados.

c) Relacionar quais os recursos e competências foram mais e menos relevantes no contexto pré e pós-LDB/96. A escala variava de 1 a 7 (sendo 1 mais importante e 7 menos importante) para a classificação dos MAIS relevantes e de 8 a 10 (sendo a escala 10 menos importante) para a classificação de itens MENOS relevantes. As notas avaliadas foram resultados da média de cada recurso no total de respondentes.

d) Avaliar, em relação à utilização e desenvolvimento dos recursos assinalados no item (b), o desempenho da própria instituição. Para isto foi utilizada uma escala likert de 5 pontos, onde 1 e 5 significavam, respectivamente, péssima e excelente utilização do recurso.

e) Os procedimentos da segunda etapa constaram da classificação dos recursos identificados, na avaliação de Barney (1991) e Miller e Shamsie (1996), relevantes como tangíveis (físicos ou de inventário), intangíveis (humanos ou habilidades) e capacidades (organizacionais), confrontando-os nos períodos pré e pós-LDB/96.

O sigilo dos resultados apresentados não foi solicitado pelas instituições pesquisadas.

\section{Resultados da Pesquisa}

As quatro instituições pesquisadas são representativas do mercado mais consolidado de IES em Fortaleza, abrangendo duas instituições públicas (UFC e UECE) e duas instituições privadas (UNIFOR e CHRISTUS) com, respectivamente, 48, 28, 30 e 10 anos de existência.

\section{Sobre 'Sucesso' em Instituições de Ensino Superior}

Por meio de uma pergunta aberta, tentou-se avaliar quais os parâmetros definidores de um bom desempenho ou sucesso para as instituições de ensino superior, na mente de seus principais gestores. Esta pergunta contribuiu para maior entendimento sobre o que se espera de uma IES no Brasil, bem como introduziu o entrevistado ao universo dos objetivos esperados e recursos 
necessários para atingi-los: "Que considera você como sucesso ou bom desempenho para Instituições de Ensino Superior?"

"Formar profissionais comprometidos com o desenvolvimento humano, social e político da sociedade, além de contribuir para o processo de conhecimento nas várias áreas científicas (UECE); formar cidadãos que contribuam para uma maior justiça social (UFC); apoiar o desenvolvimento científico, econômico e social da comunidade [...] mitigando impactos negativos ambientais (UNIFOR); no curto prazo, o sucesso pode ser medido pela procura (quantidade) e nível dos ingressos (qualidade) e pela relação de trocas com as demais instituições (transferências contra e a favor)" (CHRISTUS).

As respostas encontradas variaram desde indicadores mais nobres, como contribuição para o desenvolvimento econômico, social e científico da sociedade, até características mais específicas, como baixo índice de evasão de alunos e boa avaliação no Exame Nacional de Cursos. Estas últimas foram mais notadamente declaradas pela instituição com menor tempo de existência do grupo pesquisado. De forma geral, todos os gestores sinalizaram a formação de profissionais capacitados a atender às necessidades do mercado como um índice de sucesso institucional.

\section{Sobre o Conjunto de Recursos Relevantes nos Contextos Pré e Pós-LDB/96}

Após a avaliação dos 20 recursos adaptados de Thompson e Cole (1997), os entrevistados priorizaram os seguintes recursos importantes para o contexto atual, pós-LDB/96.

\section{Gráfico 1: Competências MAIS Relevantes PÓS-LDB/96}

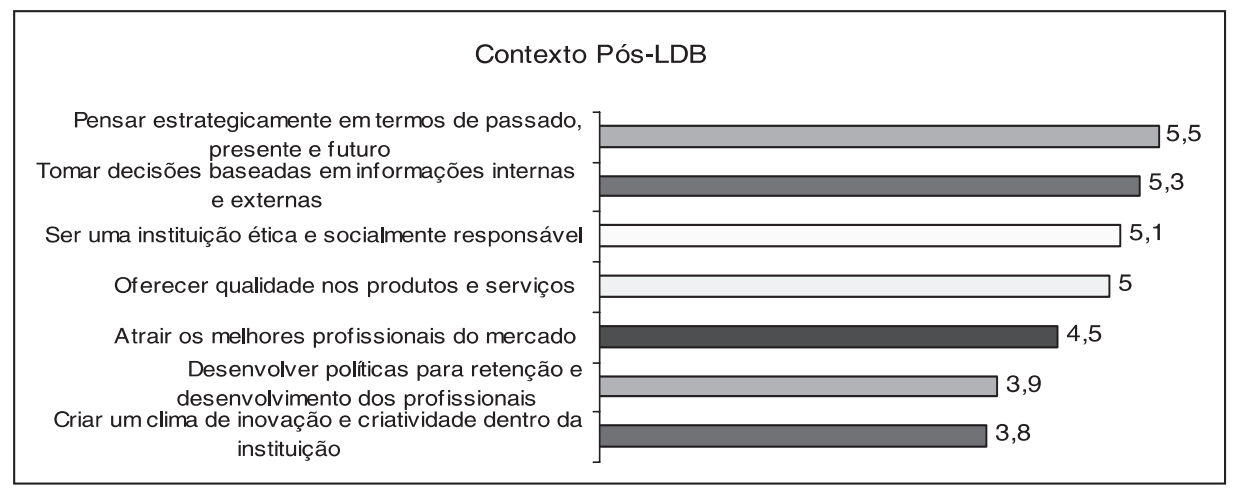

Fonte: dados da pesquisa. 
Já o contexto pré-LDB/96 revelou os seguintes recursos:

\section{Gráfico 2: Competências MAIS Relevantes PRÉ-LDB/96}

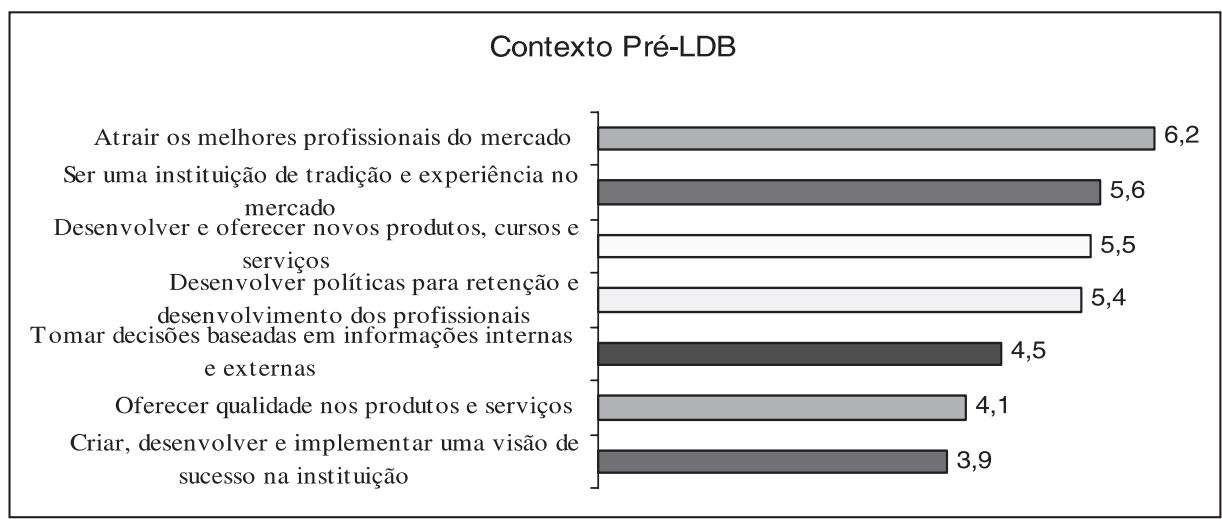

Fonte: dados da pesquisa.

A análise comparativa desses dois momentos revela um conjunto base de recursos (4 dentre 7) importantes em quaisquer dos contextos ambientais, relativos à atração e retenção dos melhores profissionais, à qualidade dos produtos e serviços e à tomada de decisões baseadas em informações internas e externas. No entanto, apesar deste conjunto comum, a ordem de importância desses recursos varia de acordo com cada contexto. A avaliação do ambiente interno e externo, primordial nos dias de hoje, era apenas desejável no passado. Já a atração dos melhores profissionais constituía o fator diferenciador no contexto Pré-LDB/96, enquanto, atualmente, representa apenas mais um dos requisitos necessários ao sucesso para uma Instituição de Ensino Superior.

Os recursos que diferem em cada contexto evidenciam as características díspares de cada época. A necessidade estratégica de obtenção de vantagem competitiva em ambientes futuros, bem como a imperiosa demanda por inovação e criatividade são os atributos representativos do cenário contemporâneo de competição. O surgimento de fatores como ética e responsabilidade social também demonstram as preocupações, legítimas ou não, emergentes de uma nova era do desenvolvimento econômico.

De outra forma, os recursos estratégicos do momento pré-LDB/96 estimulavam a consolidação da instituição por meio de sua tradição, experiência renomada e pioneirismo. Oferecer novos cursos e serviços em um mercado de pouca oferta constituía importante diferencial.

Se a avaliação dos recursos considerados mais importantes para o sucesso das IES, nos momentos Pré e Pós-LDB/96, revela as necessidades de cada época, a 
análise dos recursos considerados menos relevantes também auxilia na compreensão dos diferentes contextos ambientais.

Foram identificados como recursos menos importantes atualmente: espaço físico, localização e tradição no mercado. No passado, foram: acompanhar as mudanças do ambiente competitivo, operar de forma ambientalmente responsável e escolher um posicionamento sobre como e onde competir.

\section{Gráfico 3: Competências MENOS Relevantes PÓS-LDB/96}

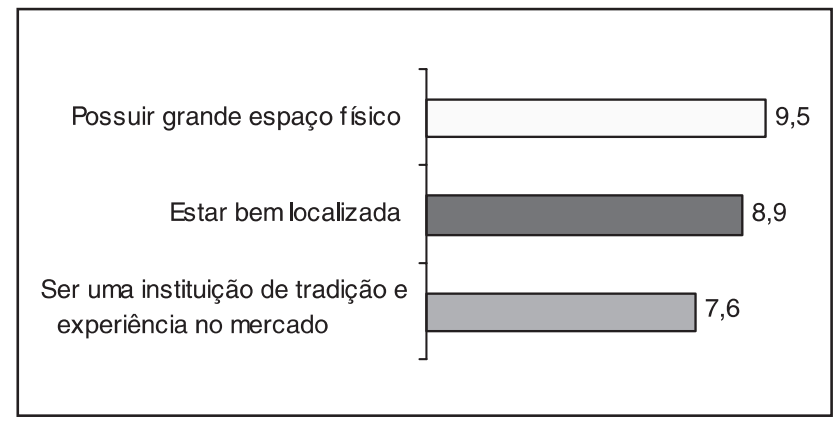

Fonte: dados da pesquisa.

\section{Gráfico 4: Competências MENOS Relevantes PRÉ-LDB/96}

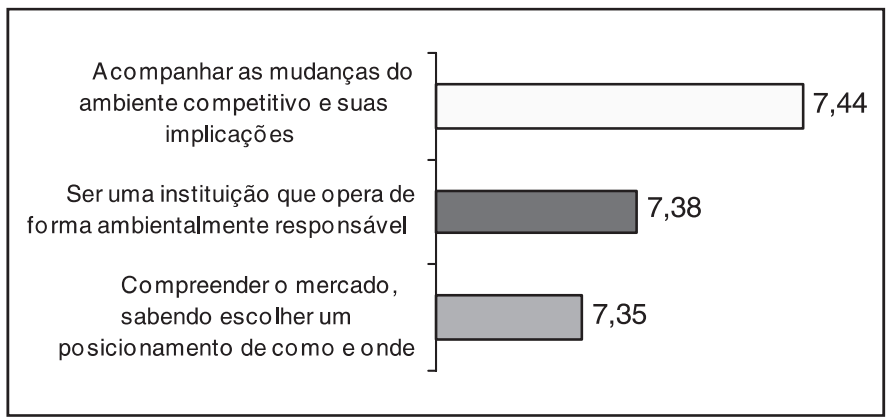

Fonte: dados da pesquisa.

A comparação dos gráficos de recursos MAIS e MENOS relevantes sugere que um dos recursos menos relevantes no contexto atual (tradição e experiência) representou papel importante no período pré-LDB/96. De forma diferente, a necessidade de compreensão do mercado e escolha de um posicionamento estratégico, menos relevantes no momento pré-LDB, constituem, na atualidade, competências necessárias às Instituições de Ensino Superior.

A tentativa de comparação dos recursos relevantes entre instituições privadas 
e públicas não demonstra diferenças muito significativas. Dentre o conjunto de recursos considerados relevantes no momento atual, nota-se a inclusão de duas novas competências: uma evidenciada apenas pelas instituições particulares: compreender o mercado, sabendo escolher um posicionamento de como e onde competir, e outra apenas pelas instituições públicas: ser uma instituição que opera de forma ambientalmente responsável. Essas escolhas podem ser explicáveis pelas características intrínsecas dos perfis diversos de cada grupo: um caráter mais mercadológico nas IES privadas e uma imagem mais socialmente responsável como contraprestação ao orçamento nas IES públicas.

\section{Sobre a Auto-avaliação das Instituições nas Competências Mais Relevantes}

Após a identificação dos recursos mais importantes para o sucesso das IES no momento atual, os entrevistados procederam a uma avaliação da própria instituição sobre esses recursos.

\section{Gráfico 5: Auto-avaliação da UFC nas Competências Mais Relevantes para o Contexto Atual. Média $=3,5$}

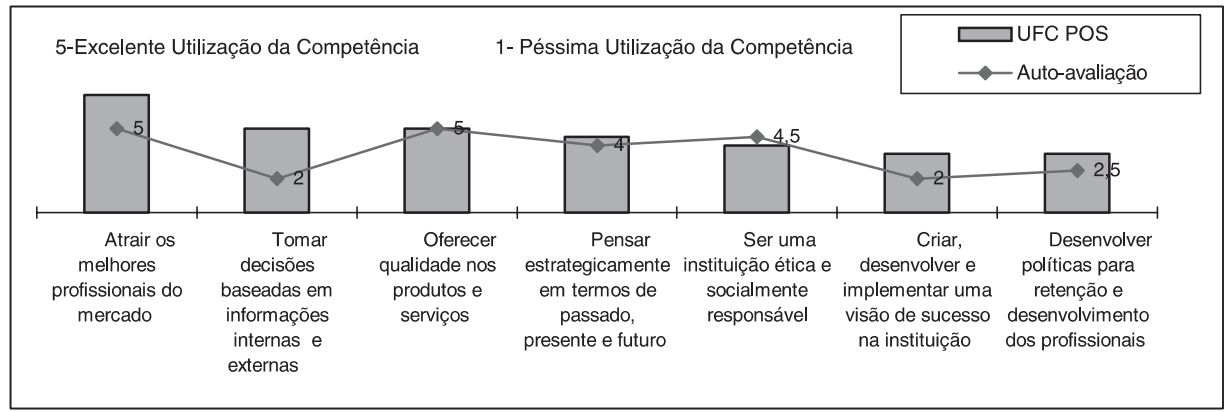

Fonte: dados da pesquisa.

\section{Gráfico 6: Auto-avaliação da UECE nas Competências Mais Relevantes para o Contexto Atual. Média = 3,0}

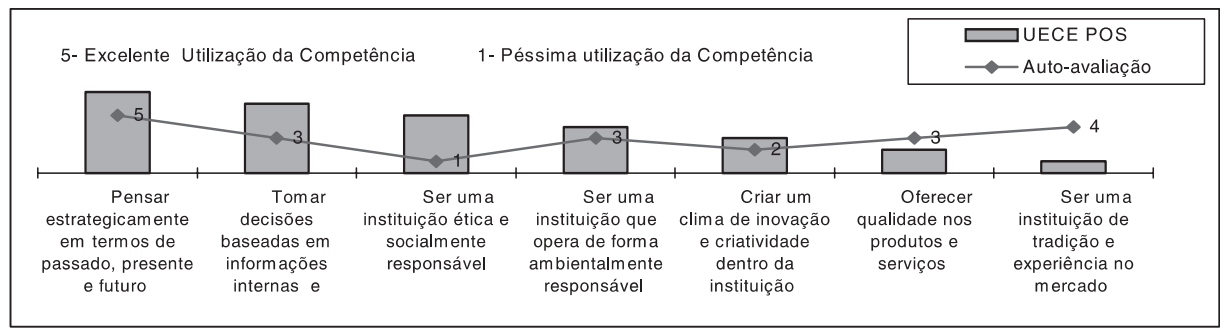

Fonte: dados da pesquisa. 


\section{Gráfico 7: Auto-avaliação da UNIFOR nas Competências Mais Relevantes para o Contexto Atual. Média $=4,0$}

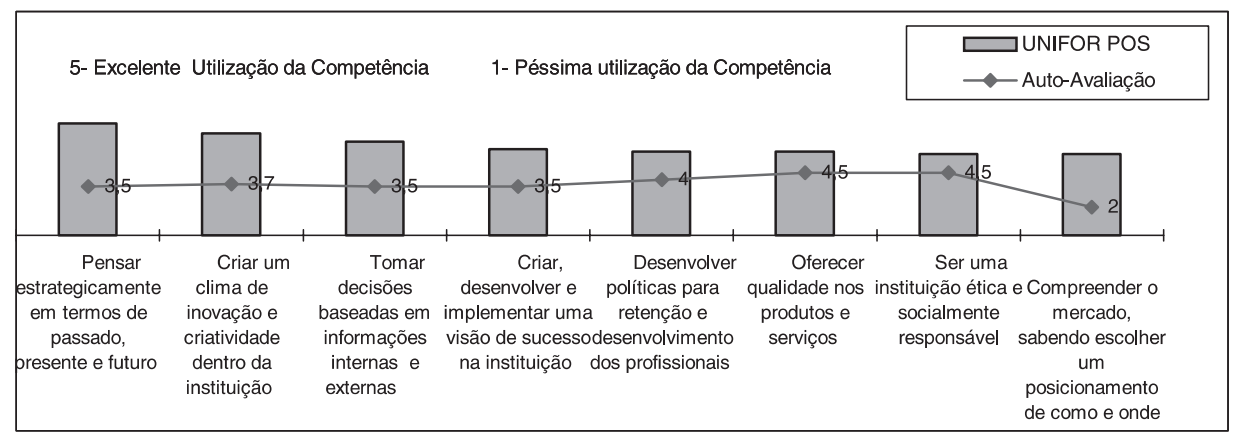

Fonte: dados da pesquisa.

\section{Gráfico 8: Auto-avaliação da CHRISTUS nas Competências Mais Relevantes para o Contexto Atual. Média $=4,4$}

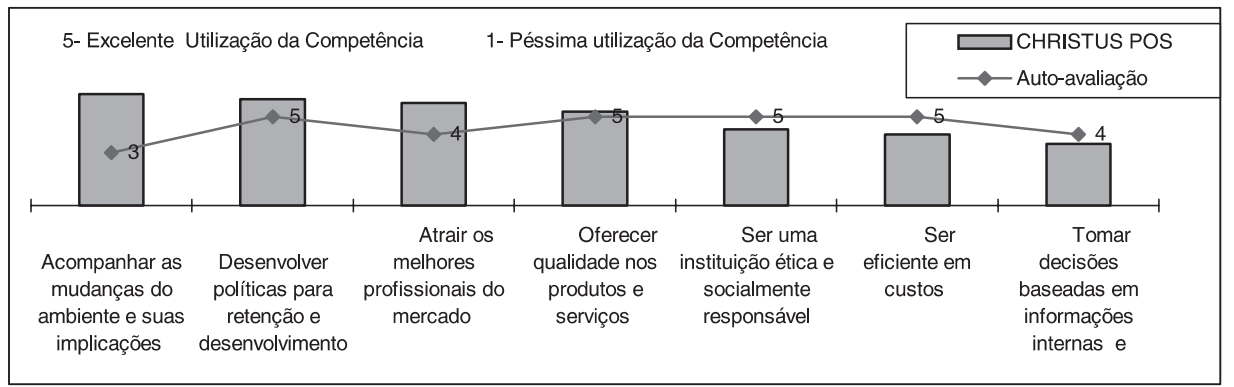

Fonte: dados da pesquisa.

De forma geral, as instituições privadas avaliaram-SE mais positivamente do que as instituições públicas, sendo a mais recente a que melhor se avaliou.

Os recursos de melhor aproveitamento, na visão de seus gestores, explicitamse em seguida.

UECE: Pensamento estratégico em termos de presente, passado e futuro; UFC: Atração dos melhores profissionais e Qualidade nos produtos e serviços; UNIFOR: Qualidade nos produtos e serviços e Ser uma instituição ética e responsável; CHRISTUS: Retenção de bons profissionais, Qualidade nos produtos e serviços e Ser uma instituição ética e socialmente responsável.

A maioria das instituições considera seus serviços de boa qualidade, enquanto somente as privadas parecem querer ressaltar a questão ética e de responsabilidade social. Isto talvez possa explicar-se pela existência da imagem 
natural de contraprestação social mais fortemente associada às instituições públicas. Por esta razão, as instituições particulares se veriam obrigadas a reforçar esse atributo.

Os baixos índices em inovação e criatividade (UECE), decisões baseadas em informações externas e internas (UFC) e compreensão do mercado (UNIFOR) podem sugerir inércia e falta de claro posicionamento das instituições para concorrerem no atual ambiente competitivo deste mercado.

\section{Sobre a Tipologia dos Recursos Considerados Relevantes nos Contextos Pré e Pós-LDB/96}

A seleção das competências mais importantes para o sucesso de uma IES, nos ambientes pré e pós LDB/96, foi caracterizada por dois tipos de recursos:

Figura 9: Tipos de Recursos MAIS Relevantes Ontem e Hoje

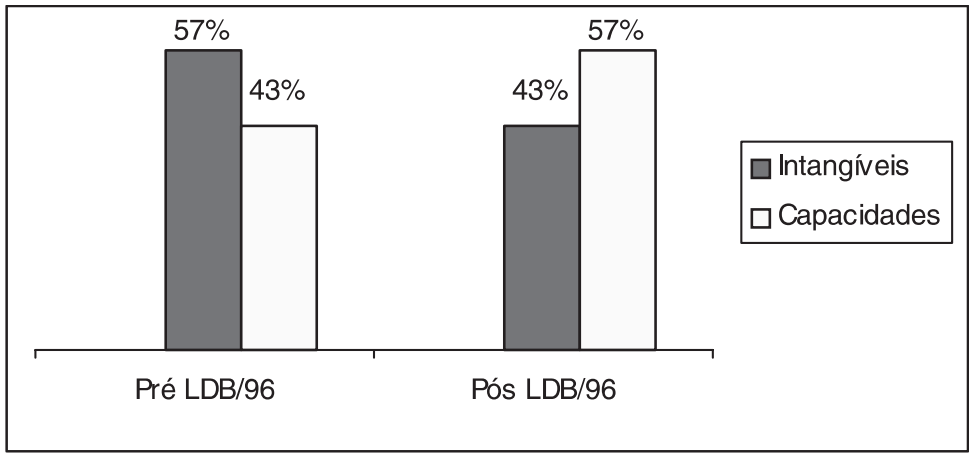

Fonte: dados da pesquisa.

As respostas dos gestores indicaram a tendência atual de maior valorização das capacidades geradoras de vantagens competitivas futuras sobre os próprios ativos intangíveis. Nenhum tipo de recurso tangível foi contemplado como um dos sete mais importantes recursos, qualquer que fosse o contexto ambiental.

Corroborando esse resultado, encontra-se a análise dos tipos de recursos considerados menos importantes para o bom desempenho de uma IES: 


\section{Figura 10: Tipos de Recursos MENOS Relevantes Ontem e Hoje}

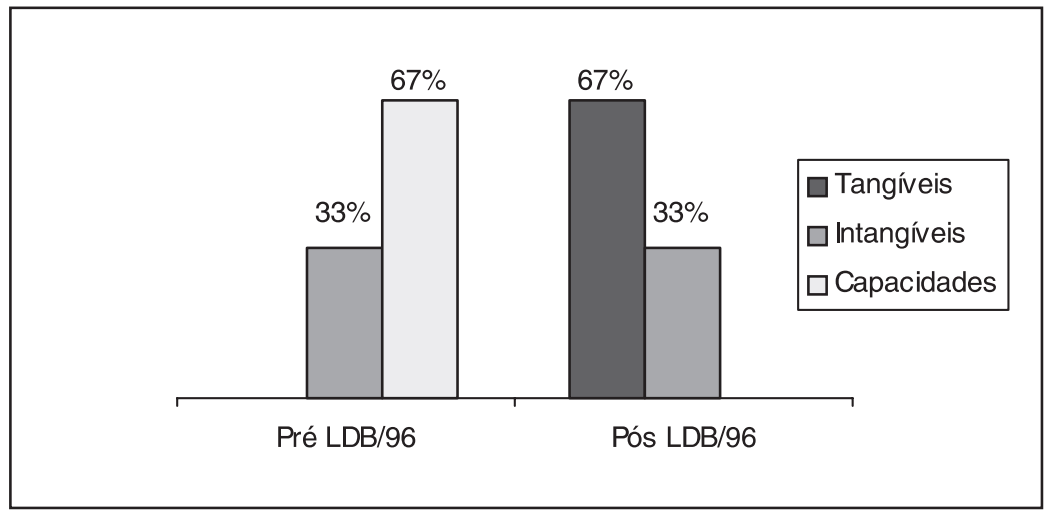

Fonte: dados da pesquisa.

No cenário pré-LDB/96, as chamadas Capacidades foram os recursos considerados de menor relevância para o desempenho das IES. De forma diversa, na era de concorrência mais acirrada, pós-LDB/96, a reunião de recursos Tangíveis não representa nenhum tipo de vantagem duradoura para as instituições.

De forma semelhante aos achados de Miller e Shamsie (1996), os recursos mais importantes para o desempenho empresarial, em ambientes de maior imprevisibilidade ou competição são as Capacidades ou Recursos Baseados em Conhecimento.

\section{CONCLUSÃo}

A revisão da literatura e as evidências empíricas do presente estudo sinalizam a identificação de recursos diferentes em distintos momentos de inflexão estratégica. No entanto percebe-se que as dicotomias não são sempre perfeitas. A análise dos resultados ressalta diferenças importantes nos recursos necessários às IES nos períodos pré e pós-LDB/1996. Não é mais possível pensar o futuro de uma instituição de ensino superior em Fortaleza como se pensava este mercado antes da LDB/96. Entretanto é preciso notar que certos recursos ainda são específicos ao negócio, independentemente dos contextos apresentados, e que ganham ou perdem relevância conforme o ambiente, mas continuam fazendo parte do núcleo de competências indispensáveis ao sucesso de uma IES. Pode ser que a evolução de novas formas competitivas chegue, um dia, a anular esse conjunto de recursos fundamentais. Esta pode ser uma boa sugestão de acompanhamento acadêmico. 
Apesar de a pesquisa ser de difícil generalização, pode-se perceber, com os resultados das IES de Fortaleza, a importância de identificar e desenvolver as competências de uma organização que garantam sobrevivência futura, de acordo com o contexto em que ela está inserta, o que remete ao objetivo principal da pesquisa. No período pré-LDB/96, recursos intangíveis como tradição e recursos humanos eram críticos para o sucesso das IES de Fortaleza. Atualmente, as capacidades de organização e agilidade estratégica, bem como inovação e criatividade definem as competências essenciais para se competir no mercado.

As hipóteses (1) dinamicidade dos recursos das IES e (3) priorização dos recursos intangíveis e capacidades sobre os tangíveis foram evidenciadas; e a (2) as IES públicas se avaliam melhor que as privadas, não pode ser inferida.

Esta investigação tenta contribuir para a consolidação de um corpo teórico ainda pouco fundamentado como é a VBR. As limitações da pesquisa representam as próprias dificuldades do estudo desta teoria. A complexidade dos recursos e de suas interações dificulta a compreensão do que efetivamente gera vantagem competitiva. Como gerar e manter recursos que sejam, ao mesmo tempo, dinâmicos na adequação aos diferentes contextos ambientais e sinergicamente entrelaçados, formando uma rede única e coesa de competências dificilmente imitáveis? Muitas perguntas continuam sem respostas, mas cabe à comunidade acadêmica tentar traduzir essas diferentes perspectivas da estratégia organizacional.

Sugerem-se, ainda, pesquisas similares em outros Estados que contemplem IES, como PUCs - Pontifícia Universidade Católica e ainda IES estrangeiras.

\section{Artigo recebido em 08.12.2004. Aprovado em 09.02.2006.}

\section{ReferênCIAS BibliográficAs}

Amit, R., \&

Schoemaker, P. J. (1993).

Strategic assets and organisational rent. Strategic Management Journal, 14(1), 33-46.

Ansoff, I. (1990).

A nova estratégia empresarial. São Paulo: Atlas.
Barney, J. (1986).

Organizational culture: can it be a source of sustained competitive advantage? Academy of Management Review, 11(3), 656-665.

Barney, J. (1991).

Firm resources and sustained competitive advantage. Journal of Management, 17(1), 99-120. 
Ministério da Educação / Instituto Nacional de Estudos e Pesquisas Educacionais Anísio Teixeira. (2005).

Sinopse estatística da educação superior graduação - 1995 a 2003. Brasília, DF, Brasil. Recuperado em 31 janeiro, 2005, de http:// www.inep.gov.br/superior/ censosuperior/sinopse/default.asp

Carneiro, J.,

Cavalcanti, M. A., \&

Silva, J. (1997).

Porter revisitado: análise crítica da tipologia do mestre. Revista de Administração Contemporânea, 1(3), 7-30.

Chaharbaghi, K., \&

Lynch, R. (1999).

Sustainable competitive advantage: towards a dynamic resource-based strategy. Management Decision, 37(1), 45-50.

Collis D. J., \&

Montgomery, C.A. (1995).

Competing on resource strategy in the 1990s. Harvard Business Review, 73(4), 118-128.

Fahy, J. (2000).

The resource-based view of the firm: some stumbling blocks on the road to understanding sustainable competitive advantage. Journal of European Industrial, 24(2/3/4), 94-104.

Forte, S. H. A. C. (2001, setembro).

Estratégias empresariais das maiores empresas do Estado do Ceará. Uma avaliação na virada do milênio. Anais do Encontro Nacional da Associação Nacional de Pós-Graduação e Pesquisa em Administração, Campinas, SP, Brasil, 25.
Forte, S. H. A. C.,

Oliveira, A. M. A., \&

Silva, A. F. (2003, setembro).

A criação do centro digital como estratégia para obtenção de vantagem competitiva sustentável: um estudo de caso no Governo do Ceará. Anais do Encontro de Estudos em Estratégia, Curitiba, PR, Brasil, 1.

Forte, S. H. A. C.,

Pereira, M. S., \&

Aquino, P. (2003, setembro).

A construção e disseminação da missão nas instituições de ensino superior do Ceará. Anais do Encontro Nacional da Associação Nacional de Pós-Graduação e Pesquisa em Administração, Atibaia, SP, Brasil, 27.

Foss, N., \&

Knudsen, T. (2003).

The resource-based tangle: towards a sustainable explanation of competitive advantage. Managerial and Decision Economics. 24(4), 291-307.

Ghemawat, P. (2001).

O cenário e a estratégia de negócios. Porto Alegre: Bookman.

Gil, A. C. (1999).

Métodos e técnicas em pesquisa social. São Paulo: Atlas.

Grant, R. (1991).

The resource-based theory of competitive advantage: implications for strategy formulation. California Management Review, 33(3), 114-135.

Grawitz, M. (1975).

Métodos y técnicas de las ciencias sociales. Barcelona: Hispano Europa. 
Kay, J. (1993).

The structure of strategy. Business Strategy Review. 4(2), 17-37.

Kotelnikov, V. (2003).

Strategic management: resourcebased model. Free business e-coach. Recuperado em 5 agosto, 2003, de http://www.1000ventures.com/ b u s i n e s s - g u i d e / mgmt_strategic_resource-based.html

Malhotra, N. K. (2001).

Pesquisa de marketing - Uma orientação aplicada. Porto Alegre:

Bookman.

\section{Miller, D., \&}

Shamsie, J. (1996).

The resource-based view of the firm in two environments: the Hollywood film studios from 1936 to 1965. Academy of Management Journal, 39(3), 519-541.

Nieto, M., \&

Perez, W. (2002).

A firm's assets as a foundation for strategy. The Learning Organization, 9(1), 19-28.

Penrose, E. T. (1959).

The theory fo the growth of the firm. New York: Wiley.

Peteraf, A. (1993).

The cornerstones of competitive advantage: a resource-based view. Strategic Management Journal, 14(3), 179-191.

Porter, M. (1986).

Estratégia competitiva. Rio de Janeiro: Campus.
Prahalad, C., \&

Hamel, G. (1990).

The core competence of the corporation. Harvard Business Review, 68(3), 79-91.

Priem, R., \&

Butler, J. (2001).

Is the resource-based view a useful perspective for strategic management research? The Academy of Management Review, 26(1), 22-40.

Rugman, A., \&

Verbeke, A. (2002).

Edith Penrose's contribution to the resource-based view of strategic management. Strategic Management Journal, 20(8), 769-780.

Thompson, J., \&

Cole, M. (1997).

Strategic competency - the learning challenge. Journal of Workplace Learning, 9(5), 153-162.

Vasconcelos, F. C. de, \&

Cyrino, Á. B. (2000).

Vantagem competitiva: os modelos teóricos atuais e a convergência entre estratégia e teoria organizacional. Revista de Administração de Empresas, 40(4), 30-37.

Weinberg, M. (2000, dezembro, 16).

Recorde histórico: proliferam as novas faculdades e o número de universitários nunca foi tão grande. Revista Veja, pp. 98-101.

Wernerfelt, B. (1984).

A resource-based view of the firm. Strategic Management Journal, 5(2), 171-180. 
